Note: This is a pre-copy-editing, author-produced PDF of an article accepted for publication in Drugs: education, prevention and policy following peer review. The definitive publisher-authenticated version [Cox $G$ and Comiskey C (2007) Characteristics of opiate users presenting for a new treatment episode: Baseline data from the national drug treatment outcome study in Ireland (ROSIE), Drugs: education, prevention and policy, 14(3): 217-230] is available online at

http://www.informaworld.com/smpp/content $\sim \mathrm{db}=a l l \sim$ content=a779361061

\title{
Characteristics of opiate users presenting for a new treatment episode: Baseline data from the national drug treatment outcome study in Ireland (ROSIE)
}

\author{
GEMMA COX \& CATHERINE COMISKEY \\ National University of Ireland, Maynooth, County Kildare, Ireland
}

Published in Drugs: education, prevention and policy, June 2007; 14(3): 217-230

Copyright: Informa healthcare

\begin{abstract}
Aim: The Research Outcome Study in Ireland (ROSIE) is the first large-scale, prospective, multisite, drug treatment outcome study in Ireland.

Method: Using a structured questionnaire, the substance use, health, crime and social problems of 404 opiate users were assessed at treatment intake (6 months, 1 year and 3 years later).

Findings: While the majority of study participants were opiate users, poly-drug use was the norm $(76 \%, n=308)$. Most participants had a history of injecting drug use $(77 \%, n=308)$, however only $42 \%(n=170)$ reported injecting in the preceding 90 days. Participants reported a range of mental and physical health complaints and extensive contact with social care services. High crime rates were observed. Analysis revealed differences in the characteristics and substance use of participants across treatment modality.

Conclusions: The range and severity of problems affecting individuals commencing treatment for their problem drug use highlights the complex needs of the cohort. These problems create substantial costs for providers of social care services in Ireland and can affect treatment outcomes.
\end{abstract}

Keywords: Treatment, outcome, opiates, crime, health

\section{Introduction}

In Ireland estimates of the numbers of opiate users have remained relatively consistent at 14,000 from 1996 (Comiskey, 2001) to the present (Kelly, Carvalho, \& Teljeur, 2003). However, the numbers presenting for treatment over the same time period have more then doubled. Recognition of the harms associated with problem drug use, and the chronic nature of this condition, has lead to increased availability of treatment and/or rehabilitative services in Ireland under the National Drug Strategy (2001). Although international studies support the overall effectiveness of established treatment options available for problem drug users (Anglin, Hser, \& Grella, 1997; Gossop, Marsden, Stewart, \& Kidd, 2003; Hubbard, Craddock, Flynn, Anderson, \& Etheridge, 1997; Teesson et al., 2006), to date, no national longitudinal data have been available to determine the effectiveness of such treatment options in the Irish context.

Treatment evaluation research has traditionally relied upon outcome studies as a logical first step in understanding effectiveness. The Research Outcome Study in Ireland (ROSIE) is the country's first national, longitudinal drug treatment outcome study. The study will provide extensive information about the pre-treatment problems of individuals being treated in the national drug treatment system 
and will make available outcome data on the impact of treatment 6 months, 1 year and 3 years post-treatment intake. This study is part of an established research tradition and follows similar international studies such as DATOS (http://www.datos.org/), NTORS and more recently DTORS (http:// www.dtors.org.uk/NTORS.aspx) and DORIS (http://www.gla.ac.uk/drugmisuse/DORIS.html).

This paper provides a detailed demographic, drug using and social profile of 404 opiate users and highlights the types of problems presented by this large, national cohort of service users. Differences between the characteristics and problems presented by these service users at treatment intake, across the main treatment modalities are also examined.

\section{Methods}

\section{Agencies}

Between September 2003 and July 2004, 404 new drug treatment clients completed baseline interviews for the ROSIE study. Recruitment occurred in both in-patient (hospitals, residential programmes and prisons) and out-patient settings (community and health board clinics, and GPs), across four modalities: methadone $(53 \%, n=215)$; supervised detoxification programmes $(20 \%$, $n=81)$; abstinence-based programmes $(20 \%, n=82)$; and needle exchanges $(7 \%, n=26)$. All four modalities of treatment were available to clients within some of the larger treatment agencies. Within the abstinence-based modality baseline study recruitment was carried out in twelve abstinence-based treatment settings; nine of which were residential drug treatment programmes and three were non-residential facilities. The residential programmes were provided by a number of different organizations and were based on different ideologies, for example, 12-Step and Minnesota Model-type treatment, a therapeutic community and Christian-based programmes. Treatment length within these programmes varied from short term (4 weeks) to long-term (over 1 year).

Treatment agencies were purposively (not randomly) sampled to reflect the known geographical spread of provision and range of services. In total, 44 agencies providing approximately 54 services located in rural, urban and inner-city areas of Ireland were involved in the study. Two criteria for agency participation were location of the service, and capacity to recruit individuals to the study within the restricted time period. Many agencies were full to capacity and were unable to facilitate new clients over the study period, hence recruitment numbers in these agencies were very low.

\section{Participants}

Client eligibility criteria for the study included: (a) being over 18 years of age; (b) starting a new treatment episode; (c) prepared to consent to the tracking/ follow-up procedures; and (d) prepared to provide a range of locator information. The study design did not include random allocation of participants to treatment. Prior to commencing baseline interviews potential participants were given an information sheet about the research, were fully informed of the study requirements and asked to sign a consent form. Individuals were not financially reimbursed at baseline interview. In this paper, data is first presented for the study population. When comparisons were made across modality, individuals recruited through needle exchange $(n=26)$ were excluded.

\section{Coverage}

At a national level, a database on all drug treatment episodes in a calendar year are maintained by the National Drug Treatment Reporting System (NDTRS) of the Drug Misuse Research Division of the Health Research Board. Compliance with the NDTRS requires that one form be completed for each person who received treatment for problematic drug use at each treatment centre. Service providers collect data at an agency level and the staff of the NDTRS compiles anonymous aggregated data at national level.

NDTRS reports that there were 4900 cases commencing/recommencing treatment for problem drug use (not specifically opiate use) in 2003, giving the ROSIE study a minimum national coverage rate of $8.2 \%$ of all new treatments. In addition, 1265 of these cases commenced/recommenced methadone treatment. As 215 of the ROSIE participants were recruited within the methadone 
modality, the study has a national coverage rate of approximately $17 \%$ of all new methadone treatments. The NDTRS reports that 682 of the 4900 cases commenced a detoxification programme. Eighty-one ROSIE participants were recruited from this modality, giving a national coverage of approximately $12 \%$. The NDTRS figures are based on a calendar year, and data for 2004 is at present unavailable. Given this limitation, the data do provide some information on the scale of the ROSIE study. The coverage rates within ROSIE are well in excess of other national treatment outcome studies, where rates are seldom published, but are estimated to be in single figures and below $5 \%$.

\section{Instrument}

A structured questionnaire assessed a range of participant characteristics. Data were based on participants self-report, a valid and reliable methodology when undertaking research on such a cohort (Del Coca \& Noll, 2000). The main outcome measures were drug-using behaviour, physical and mental health, social functioning and crime. The research instrument contained items and scales developed specifically for the study and measures adapted from published instruments (including MAP and OPI Health Scale). In addition to lifetime measures, data were collected for the 90 days prior to interview. A team of trained interviewers from the National University of Ireland, Maynooth, administered all questionnaires. Baseline interviews took approximately 1 hour to complete. A pilot study of 20 interviews was completed to highlight and measure any interviewer variability and throughout the study all interviewers were trained by the same trainer. In addition, in order to ensure data quality, a quality assurance audit of all primary data was conducted at pertinent intervals.

\section{Statistical analysis}

Continuous variables were analysed using means, standard deviation and one-way analysis of variance (ANOVA). Post hoc differences between groups were determined using Tukey's HSD test. Statistical analysis of categorical variables was conducted using frequencies and chi-square tests. Missing data were handled by excluding the cases from the particular analysis. All statistical analysis was conducted using SPSS (version 11.0) for windows.

\section{Results}

\section{Demographics}

One quarter of the study population was female $(n=102)$. The average age of participants was 28 years (median 27, range 18-57 years). On average respondents reported leaving school at 15 years, and $28 \%$ of the population were 'early school leavers'-left school before the age of 15 years. Analysis revealed that current levels of employment were low; only $16 \%$ of the population was employed (either full time or part time) at baseline interview, while $21 \%$ had been employed over the three months prior to baseline interview. The main source of income for the majority of participants $(77 \%)$ was social welfare payments. Less than one third of the cohort were living in the family home at the time of the baseline interview, and $25 \%$ were in their own or rented accommodation. Eight percent of the study population were homeless at baseline interview, however, $18 \%$ reported a period of homelessness over the preceding 3 months. The majority of respondents $(56 \%, n=216)$ reported having children under the age of 18 years. However, over half of the participants with children $(56 \%, n=121)$ did not have their children in their care.

\section{Illicit drug use}

Table I illustrates that participants reported using a range of substances in their lifetime. Opiates were the drugs most frequently used over the 90 days prior to interview $(81 \%, n=316)$. Heroin was used by $77 \%$ of the respondents, and $41 \%$ used non-prescribed methadone. Poly-drug use was the norm $(76 \%, n=308)$.

The majority of participants $(77 \%, \mathrm{n}=308)$ reported having ever injected a drug, and most reported engaging in some form of injecting risk behaviour in their lifetime; borrowing $(63 \%, n=178)$ and lending $(53 \%, n=152)$ used needles/ syringes, sharing filters/spoons/flush water $(63 \%, n=179)$ and 
reusing own injecting equipment $(88 \%, n=250)$. Forty-two percent of the population $(n=170)$ reported injecting in the preceding 90 days. These individuals injected on average 47 out of the 90 days, and $15 \%(n=46)$ were daily injectors. Levels of recent injecting risk behaviour were substantially lower than lifetime levels. For example, only $12 \%(n=21)$ of the injecting population reported borrowing, and $6 \%(n=17)$ reported lending used needles/syringes in the preceding 90 days. Forty-six percent $(n=181)$ of the study population reported having had an accidental overdose at least once in their lifetime. Levels of recent (last 90 days) overdose were substantially lower at $7 \%(n=26)$. Alcohol use

Over half the cohort $(54 \%, n=204)$ drank alcohol in the preceding 90 days. Male drinkers consumed, in a typical drinking day, an average of 19 units $(S D=18)$, while females consumed an average of 12 units $(S D=12)$. Forty-two percent $(n=157)$ of the cohort were 'heavy drinkers'; defined as consuming six or more units on an average drinking day for a women and 8 or more units on an average day for a male. These data excluded those who did not drink at all.

Table I. Drug use for study population $(n=404)$.

\begin{tabular}{lcccccccccc}
\hline & \multicolumn{2}{c}{ Ever used } & \multicolumn{2}{c}{ Recent use } \\
& \multicolumn{3}{l}{ (last 90 days) } & \multicolumn{2}{c}{$\begin{array}{c}\text { Mean age first } \\
\text { used }\end{array}$} & \multicolumn{2}{c}{$\begin{array}{c}\text { Reported } \\
\text { problematic use }\end{array}$} & \multicolumn{2}{c}{$\begin{array}{c}\text { Mean age of first } \\
\text { problematic use }\end{array}$} \\
\cline { 2 - 11 } & $\%$ & $(\mathrm{n})$ & $\%$ & $(\mathrm{n})$ & Mean & $(\mathrm{SD})$ & $\%$ & $(\mathrm{n})$ & Mean & $(\mathrm{SD})$ \\
\hline Heroin & 99 & $(398)$ & 77 & $(306)$ & 18.3 & $(4.6)$ & 92 & $(355)$ & 20.3 & $(4.9)$ \\
Cannabis & 97 & $(375)$ & 64 & $(243)$ & 14.3 & $(3.3)$ & 30 & $(102)$ & 17.5 & $(5.3)$ \\
Cocaine & 92 & $(348)$ & 44 & $(179)$ & 19.7 & $(4.5)$ & 38 & $(123)$ & 22.0 & $(4.1)$ \\
$\begin{array}{l}\text { Ecstasy } \\
\text { a Non-prescribed }\end{array}$ & 90 & $(314)$ & 12 & $(46)$ & 17.6 & $(4.5)$ & 36 & $(103)$ & 17.6 & $(3.8)$ \\
benzodiazepines & 87 & $(324)$ & 44 & $(174)$ & 20.5 & $(4.5)$ & 42 & $(120)$ & 20.5 & $(4.5)$ \\
Non-prescribed & 86 & $(335)$ & 41 & $(161)$ & 20.4 & $(5.3)$ & 32 & $(96)$ & 22.0 & $(6.1)$ \\
methadone & & & & & & & & & & \\
Amphetamine & 80 & $(278)$ & 4 & $(17)$ & 17.4 & $(3.5)$ & 24 & $(60)$ & 17.2 & $(2.9)$ \\
Crack & 59 & $(212)$ & 15 & $(59)$ & 22.6 & $(4.8)$ & 29 & $(55)$ & 22.2 & $(4.2)$ \\
\hline
\end{tabular}

Note: ${ }^{a}$ This includes the misuse of prescribed benzodiazepines.

\section{Contact with treatment service}

Most participants $(87 \%, n=352)$ had previously sought treatment for their drug use. Previous treatment included: methadone maintenance $(59 \%, n=236)$; supervised detoxification $(52 \%$, $n=205)$; counselling $(61 \%, n=243)$; and residential drug treatment $(32 \%, n=127)$. Participants also reported contacting other social care services over the previous 12 months. This included attending an A\&E Department (43\%, $n=174)$, a GP $(52 \%, n=207)$, an out-patients' appointment $(22 \%, n=89)$, a hospital admission $(26 \%, n=104)$, contact with housing/ homeless services $(28 \%, n=111)$, and social welfare services $(47 \%, n=189)$.

Physical and mental health

Participants reported suffering from a range of physical and mental health complaints. The most frequently reported physical health symptoms were poor appetite $(72 \%, n=268)$ and feeling tired/fatigued $(72 \%, n=268)$. One third of the cohort reported suffering from these health problems on a daily basis. Regarding mental health complaints, over half the cohort reported feeling hopeless about the future $(56 \%, n=196)$, feelings of worthlessness $(53 \%, n=188)$, and having no interest in things $(57 \%, n=206)$. In addition, $25 \%(n=88)$ of respondents had suicidal thoughts over the 90 days prior to interview. One third of the cohort reportedly attempted suicide in the past $(33 \%, n=127)$ and $19 \%(n=39)$ attempted suicide in the preceding six months.

\section{Crime}

The vast majority of participants $(90 \%, n=339)$ committed some form of crime in their lifetime (excluding drug possession and driving-related offences); $76 \%$ committed an acquisitive crime $(n=291)$ and $70 \%$ dealt/supplied drugs $(n=243)$. The proportions of respondents reporting recent involvement in crime were substantially lower across all categories of offences. For example, only 
$28 \%(n=105)$ of the cohort reportedly committed an acquisitive crime in the 90 days prior to baseline interview, while $30 \%(n=109)$ reportedly dealt drugs over the same time period.

Seventy-six percent $(n=285)$ of participants reported having been arrested for an offence, $18 \%$ $(n=69)$ reported an arrest in the preceding 90 days. However, $48 \%$ of respondents reported having outstanding legal problems at treatment intake $(n=219)$. In addition levels of imprisonment were high, and $65 \%(n=253)$ of respondents had a prison history.

Participant differences across treatment modalities

Table II illustrates the demographic and treatment variables by modality. Significant gender differences were observed, with the highest proportion of men being in abstinence-based treatment and the lowest in methadone programmes. Participants in the detoxification group were significantly younger than those in methadone treatment. Analysis revealed that higher proportions of those in methadone treatment were homeless at the time of interview than those in other modalities.

Participants in this modality were also less likely to report having any educational qualifications and were more likely to have children.

Table II. Demographic and treatment variables by modality.

\begin{tabular}{|c|c|c|c|c|c|c|c|c|}
\hline \multirow[b]{2}{*}{ Demographics } & \multicolumn{2}{|c|}{$\begin{array}{l}\text { Modality } \\
\text { Methadone } \\
(\mathrm{n}=215)\end{array}$} & \multicolumn{2}{|c|}{$\begin{array}{c}F / x \text { value } \\
\text { Detoxification } \\
(n=81)\end{array}$} & \multicolumn{2}{|c|}{$\begin{array}{c}\text { P-value } \\
\text { Abstinence } \\
(n=82)\end{array}$} & & \\
\hline & $\%$ & $(\mathrm{n} / \mathrm{SD})$ & $\%$ & $(n / S D)$ & $\%$ & $\mathrm{n}$ & & \\
\hline \%Male & 68 & $(147)$ & 77 & $(62)$ & 89 & (73) & 13.5 & $0.00^{\star \star}$ \\
\hline Age (SD) & 28 & (6.6)a & 26 & (5.9)a & 27 & $(5.1)$ & 3.7 & $0.02^{*}$ \\
\hline $\begin{array}{l}\text { \%No educational } \\
\text { Qualifications }\end{array}$ & 40 & $(82)$ & 22 & (18) & 21 & $(17)$ & 17.2 & $0.00^{\star *}$ \\
\hline$\%$ Currently homeless & 12 & (25) & 3 & (2) & 1 & (1) & 175.3 & $0.00^{* *}$ \\
\hline \%Inprisoninlast90days & 8 & (17) & 19 & (15) & 20 & (16) & 9.7 & $0.00^{\star *}$ \\
\hline$\%$ Have children & 64 & (130) & 47 & (37) & 47 & (36) & 9.5 & $0.00^{* *}$ \\
\hline Treatment variables & & & & & & & & \\
\hline $\begin{array}{l}\% \text { On waiting list to } \\
\text { access index treatment }\end{array}$ & 57 & (120) & 79 & (64) & 66 & (52) & 12.6 & $0.00^{* *}$ \\
\hline $\begin{array}{l}\text { Time on waiting list- } \\
\text { weeks (SD) }\end{array}$ & 11 & (22.6)a & 7 & (10.4) & 5 & $(7.7)^{\mathrm{a}}$ & 4.1 & $0.02^{*}$ \\
\hline $\begin{array}{l}\% \text { Had previous drug } \\
\text { treatment }\end{array}$ & 83 & (177) & 95 & (77) & 92 & (75) & 9.7 & $0.00^{* *}$ \\
\hline Previous treatments & & & & & & & & \\
\hline Methadone maintenance & 58 & (123) & 65 & (52) & 51 & (42) & 3.1 & 0.21 \\
\hline Structured detoxification & 43 & (91) & 64 & (51) & 61 & (49) & 13.3 & $0.00^{\star *}$ \\
\hline Residential treatment & 22 & (46) & 33 & (27) & 58 & (47) & 35.2 & $0.00^{* *}$ \\
\hline One-to-one counselling & 53 & (113) & 75 & (61) & 67 & (55) & 13.8 & $0.00^{* *}$ \\
\hline
\end{tabular}

Note: Levels of significance are shows as ${ }^{*} \mathrm{p}<0.05 ;{ }^{* *} \mathrm{p}<0.01$.

${ }^{a}$ Means on the same row and sharing the same superscript letter differ significantly at $p<0.05$ (Tukey HSD test).

Table II also shows that participants in the methadone modality were less likely to have previously sought treatment for their drug use, and to have presented at all forms of treatment, except methadone. Although participants in methadone treatment were less likely to have been on a waiting list prior to commencing their index treatment, those that were, spent significantly longer waiting to access treatment than their counterparts.

There were no statistically significant differences across modalities in lifetime use or the mean age of first use of any illicit substances. However there were significant differences in the proportions reporting problematic use of certain drugs. Participants starting methadone treatment were more likely to report their heroin use as problematic $\left(x^{2}=8.9, p<0.05\right)$. Conversely, participants in abstinence-based programmes were more likely to report problematic use of methadone $\left(x^{2}=23.2, p\right.$ $<0.01)$, cocaine $\left(x^{2}=21.9, p<0.01\right)$, cannabis $\left(x^{2}=36.8, p<0.01\right)$, and alcohol $\left(x^{2}=25.9, p<0.01\right)$. 
Table III shows some statistically significant differences in recent (last 90 days) substance use across modality. Not only were participants in methadone treatment more likely to have used heroin and cannabis but they also reported using both drugs on more days than those in the abstinence and detoxification modalities (heroin $F=12.3, p<0.01$; cannabis $F=3.6, p<0.05$ ). Participants in the abstinence-based modality were less likely to report recent poly-drug use and injecting drug use. There were no significant differences in recent injecting risk behaviour across modality, however the abstinence group reported higher rates of lifetime risk behaviours: borrowing $\left(x^{2}=18.1, p<0.01\right)$ and lending $\left(x^{2}=10.4, p<0.01\right)$ used injecting equipment, and sharing filters/spoons/flush water $\left(x^{2}=12.8, p<0.01\right)$.

Table III. Injecting risk behaviour by modality.

\begin{tabular}{|c|c|c|c|c|c|c|c|c|}
\hline & \multicolumn{2}{|c|}{$\begin{array}{c}\text { Modality } \\
\text { Methadone } \\
(n=215)\end{array}$} & \multicolumn{2}{|c|}{$\begin{array}{c}\text { F/x values } \\
\text { Detoxification } \\
\quad(n=81)\end{array}$} & \multicolumn{2}{|c|}{$\begin{array}{c}\text { p-values } \\
\text { Abstinence } \\
(n=82)\end{array}$} & & \\
\hline & $\%$ & $\mathrm{n}$ & $\%$ & $\mathrm{n}$ & $\%$ & $\mathrm{n}$ & & \\
\hline$\%$ Used $^{\mathrm{a}}$ Heroin & 82 & $(175)$ & 75 & $(61)$ & 58 & $(45)$ & 17.8 & $0.00^{* *}$ \\
\hline Methadone & 44 & (95) & 46 & (37) & 31 & (25) & 4.9 & 0.08 \\
\hline Benzodiazepines & 45 & (95) & 51 & $(41)$ & 35 & (28) & 4.4 & 0.11 \\
\hline Cocaine & 40 & (85) & 49 & (40) & 46 & (36) & 2.7 & 0.25 \\
\hline Crack & 15 & (32) & 14 & (11) & 17 & (13) & 0.3 & 0.87 \\
\hline Cannabis & 67 & (135) & 66 & (52) & 50 & (37) & 6.7 & $0.03^{*}$ \\
\hline Alcohol & 54 & (108) & 57 & $(46)$ & 55 & (41) & 0.2 & 0.91 \\
\hline$\%$ Poly-drug use ${ }^{a}$ & 79 & (170) & 82 & (66) & 61 & $(50)$ & 12.4 & $0.00^{* *}$ \\
\hline$\%$ Injected $^{\mathrm{a}}$ & 57 & (93) & 61 & (38) & 43 & (24) & 6.4 & $0.04^{*}$ \\
\hline$\%$ Overdosed $^{a}$ & 8 & (17) & 4 & (3) & 3 & (2) & 4.4 & 0.11 \\
\hline
\end{tabular}

Note: Levels of significance are shows as ${ }^{*} \mathrm{p}<0.05 ;{ }^{* *} \mathrm{p}<0.01 .{ }^{\mathrm{a}}$ Refers to behaviour in the 90 days preceding interview.

The reporting of physical and mental health complaints varied significantly across modality with participants in the detoxification group reporting higher rates of physical health complaints while those in abstinence-based programme were more likely to report mental health problems. For example, respondents in the detoxification group were more likely to report having a poor appetite $\left(x^{2}=15.8, p<0.01\right)$, stomach pains $\left(x^{2}=7.6, p<0.05\right)$, chest pains $\left(x^{2}=15.6, p<0.01\right)$, joint or bone pains $\left(x^{2}=22.7, p<0.01\right)$, muscle pains $\left(x^{2}=24.0, p<0.01\right)$ and numbness or tingling $\left(x^{2}=8.2, p<\right.$ $0.05)$. Conversely, participants in the abstinence group were more likely to report feeling tense $\left(x^{2}=17.3, p<0.01\right)$, suddenly scared for no reason $\left(x^{2}=11.1, p<0.01\right)$, feeling fearful $\left(x^{2}=27.7, p<\right.$ $0.01)$, nervousness or shakiness $\left(x^{2}=21.9, p<0.01\right)$, feelings of worthlessness $\left(x^{2}=10.0, p<0.05\right)$ and feeling lonely $\left(x^{2}=10.7, p<0.01\right)$.

Analysis revealed few differences when comparing self-reported crime rates across modalities. That said, respondents in the methadone group were less likely to report selling/supplying drugs in the preceding 90 days than their counterparts in detoxification and abstinence based treatments $\left(x^{2}=11.0, p<0.01\right)$. In addition, participants in abstinence-based treatment reported higher rates of assault $\left(x^{2}=11.7, p<0.01\right)$ than those in the other modalities. Individuals in detoxification and abstinence-based treatments were more likely to have outstanding legal problems at the time of interview. However, greater proportions of participants in these modalities had been in prison in the 3 months prior to interview $\left({ }^{\times 2}=9.7, p<0.01\right)$.

\section{Discussion}

The need for well-designed, planned and executed treatment outcome studies that provide scientific evidence on which to base important public-health policy has been well documented across the globe (UNDCP, 1997; EMCDDA, 1999) The data presented in this study provides the first such evidence in an Irish context. In addition the evidence presented is based on high levels of coverage of the treated population and the cohorts demographics broadly reflect the known demographics of this population. The study's 3:1 male to female gender ratio is broadly representative of the overall treatment population (Long, Lynn, \& Kelly, 2005). In addition 13\% of the ROSIE cohort was 
commencing treatment for the first time. This is comparable with the $12 \%$ of 'new cases' presenting for treatment in the HSE Eastern Region (Kelly, Lynn, \& Long, 2005), the area where most ROSIE study recruitment occurred. The analysis of the ROSIE baseline data highlights a number of key areas of concern, most notably poly-drug use, alcohol use, crime, health and service contact. However, as with any research, the results discussed must be viewed in light of any limitations. This study did not randomly allocate participants to treatment settings or modality, nor did it employ a control group (drug users with similar profile not attending the index treatment). In addition the geographical locations of the services chosen reflect the provision of services available at national level rather than being a representative sample. While these choices do place limitations on the study these limitations are acceptable and reflect similar limitation in other international outcome studies.

While the vast majority of study participants were opiate users, poly-drug use was the norm (76\%) with rates comparable to NTORS (81\%; Gossop et al., 1998). A relatively high proportion of participants (44\%) reported recent (last 90 days) cocaine use. Research suggests that opiate users who use cocaine can be distinguished from other opiate users in a number of respects; higher frequency of injecting and sexual risk behaviour (Hudgins, McCusker, \& Stoddard, 1995), greater involvement in crime (Grella, Anglin, \& Wugalter, 1997), more alcohol use (Boys, Dobson, Marsden, \& Strang, 2002), more physical and psychological health problems (Foltin \& Fischman, 1998) and increased risk of contracting HIV or other blood-borne infectious diseases ( Joe \& Simpson, 1995). High levels of cocaine use at treatment intake have also been shown to be an independent predictor of poor treatment outcomes for opiate users and pose a significant risk for relapse (Gossop et al., 2003).

Levels of recent benzodiazepine consumption were also high (44\%). Benzodiazepine poly-drug users are more likely to inject, to share injecting equipment, and to have higher risks of HIV and HCV infection (Drake, 1994; Drake, Hall, Ross, \& Wodak, 1992). Use of this class of drugs has also been found to be associated with greater psychological morbidity (Rooney, Kelly, Bamford, Sloan, \& O'Connor, 1999) and to compromise treatment outcomes (Gossop, Stewart, Browne, \& Marsden, 2002).

The ROSIE data confirms that opiate users presenting at treatment services in Ireland are primarily a poly-drug using cohort. Data also highlight the increased use of cocaine by this population. National drug treatment services must be prepared to respond to service users multiple drug use. Research suggests that drug service providers have a tendency to focus on what they perceive as being the main illicit problem drug (Miller \& Mirin, 1989). Analysis of the ROSIE follow-up data will shed some light on whether this applies in the Irish context, the impact of poly-drug use on treatment outcomes, and the extent to which treatment services are dealing with service users' multiple drug use. The goals of drug treatment in Ireland are clearly stated in the national drug strategy (National Drugs Strategy, 2001). This strategy clearly highlights the four pillars of action, supply reduction, prevention, treatment and research. The objective of treatment is two fold. First, to enable those dependent on drugs to reduce dependency, improve health and social well being and ultimately to lead a drug-free lifestyle and, second, to minimize the harm to those who continue to engage in drug taking. The outcomes from the ROSIE study will provide the first evidence on the realization of these two objectives.

As with NTORS (Gossop et al., 1998), the drinking patterns among ROSIE participants tend to be dichotomous, with relatively high proportions of non-drinkers (46\%) and heavy drinkers $(40 \%)$. Excessive alcohol use may present particular problems for opiate users, as the high rates of hepatitis $B$ and $C$ infection among this cohort is known to elevate the health risks of excessive drinking (Baffis et al., 1999). In addition, alcohol consumption increases the risk of overdose when used with other sedative drugs (Gossop, Griffiths, Powis, Williamson, \& Strang, 1996). The need to identify and respond to drinking problems among opiate users should be clearly and explicitly recognized as a requirement of drug treatment services. 
Regular and dependent use of heroin and/or cocaine is strongly related to drug supply/dealing (Ball, Sheffer, \& Nurco, 1983) and other income-generating crimes, such as acquisitive crimes ( Jarvis \& Parker, 1989). Research has indicated that drug treatment plays an important role in reducing some types of criminal behaviour (Ball \& Ross, 1991; Gossop, 2005). Although reductions in crime are not seen as specific goals of drug treatment in Ireland, an effective response to drug-driven acquisitive crime requires treatment for drug-related problems. A range of physical (Stein, 1999) and mental (Weaver, Madden, Charles, Stimpson, \& Renton, 2003) health problems are associated with problematic drug use. Study participants reported high rates of physical and mental health symptoms and extensive contact with an array of health and social care services, highlighting the multiple and often inter-related or complex needs of this cohort.

Research suggests that drug users with 'complex needs' are those attending a range of different agencies, but are less likely to be helped by any one agency. Such a client group are characterized by frequent service use and non-compliance with treatment regimes (Keene, 2001), which may have implications for treatment outcomes. Consequently they are a resource-intensive group, which provide the greatest challenge for service providers. Analysis revealed some differences in the characteristics and problems presented by service users at treatment intake to the three treatment modalities.

Participants in the methadone modality were more likely to have no educational qualification, to be homeless, and to have children. They were also more likely to report problematic heroin use, and the recent use of both heroin and cannabis at treatment intake than participants in other modalities. They were, however, less likely to have sought previous treatment for their drug use. Conversely, participants in the abstinence-based modality were more likely to be male and to consider their methadone, cocaine, cannabis and alcohol use as problematic. Although there was no significant difference in lifetime use of each class of drugs, individuals in the abstinence-based modality were more likely to have reported lifetime injecting risk behaviours. These participants were also more likely to report suffering from mental health problems and to have outstanding legal charges. On the other hand, individuals commencing a structured detoxification programme were younger than their counterparts. They were more likely to report recent poly-drug use and injecting drug use.

Respondents in this modality were also more likely to report physical health problems at the time of interview. The identified differences across modality may be due to a mixture of service referral and self-selection processes.

Analysis of ROSIE baseline data demonstrates the extent to which service users in the Irish drug treatment system present with multiple problems, many of which are both severe and chronic. The range and severity of these problems present major challenges for the services, which have primary responsibility for their management and treatment. The data presented here shows that many agencies are brought into contact with problem drug users. There is an urgent need to ensure the provision of an integrated and co-ordinated response to problem drug use. In addition, it is crucial that different drug treatment services are effectively co-ordinated and that appropriate support is obtained from a wide range of other agencies. This is ever more important in the changing, dynamic and growing multicultural Irish society of today. To capture the longer term influences on treatment outcomes the ROSIE study has recently been extended to allow for a continuing follow-up of study participants over a three-year follow-up period and future reports will present data on the impact of treatment upon the problems described in this paper. 


\section{Acknowledgements}

We thank the National Advisory Commission on Drugs (NACD) for commissioning and funding the ROSIE study and in particular the Director Mairead Lyons for her commitment to the research. We are indebted to Jennifer Cronly for her assistance in drafting this article. We would also like to thank Dr Gloria Crispino-O'Connell (Institute of Technology, Tallaght) Paul Kelly (NUI, Maynooth) and Emma White (NUI Maynooth) for their statistical advice on the study. We are particularly grateful to the staff at the 54 services where study recruitment was undertaken, without their support and cooperation the ROSIE study would not have been possible. In addition, we are indebted to all service users who agreed to take part in the ROSIE study.

\section{References}

Anglin, M., Hser, Y. I., \& Grella, C. (1997). Drug addition and treatment careers among clients in the drug abuse treatment outcome study (DATOS). Psychology of Addictive Behaviour, 11, 308323.

Baffis, V., Shrier, I., Sherker, A. H., \& Szilagyi, A. (1999). Use of interferon for prevention of hepatocellular carcinoma in cirrhotic patients with hepatitis $B$ or hepatitis $C$ infection. Annual International Medicine, 131, 696-701.

Ball, J., \& Ross, A. (1991). The effectiveness of methadone maintenance treatment. New York: Springer.

Ball, J., Sheffer, J. W., \& Nurco, D. N. (1983). The day-to-day criminality of heroin addicts in Baltimore: A study in the continuity of offence rates. Drug \& Alcohol Dependence, 12, 119-142.

Boys, A., Dobson, J., Marsden, J., \& Strang, J. (2002). 'Rich man's speed': A qualitative study of young cocaine users. Drugs: Education, Prevention \& Policy, 9, 195-210.

Comiskey, C. (2001). Methods for estimating prevalence of opiate use as an aid to policy and planning. Substance Use \& Misuse, 36, 131-151.

Del Coca, F., \& Noll, J. (2000). Truth or consequences: The validity of self-report data on health service research on addiction. Addiction, 95, S347-S360.

Drake, S. (1994). Benzodiazepine use among injecting drug users and implications. Addiction, 89, 379-382.

Drake, S., Hall, W., Ross, M., \& Wodak, A. (1992). Benzodiazepine use and HIV risk-taking behaviour among injecting drug users. Drug \& Alcohol Dependence, 31, 31-36.

EMCDDA. (1999). Evaluating the treatment of drug abuse in the European Union (Scientific Monograph Series, No. 3). Lisbon, Portugal: European Monitoring Centre for Drugs and Drug Addiction.

Foltin, R., \& Fischman, W. (1998). Effects of 'binge' use of intravenous cocaine in methadonemaintained individuals. Addiction, 93, 825-836.

Gossop, M., Trakada, K., Stewart, D., \& Witton, J. (2005). Reductions in criminal convictions after addiction traeatment: 5 year follow-up. Drug and Alcohol Dependence, Sep 1, 79, 295-302.

Gossop, M., Griffiths, P., Powis, B., Williamson, S., \& Strang, J. (1996). Frequency of non-fatal overdose: Survey of heroin users recruited in non-clinical settings. British Medical Journal, 17, 313-402.

Gossop, M., Marsden, J., Stewart, D., \& Kidd, T. (2003). The National Treatment Research Study (NTORS): 4-5 year follow-up results. Addiction, 98, 291-303.

Gossop, M., Marsden, J., Stewart, D., Lehmann, P., Edwards, C., Wilson, A., et al. (1998). Substance use, health and social problems of service users at 54 drug treatment agencies. British Journal of Psychiatry, 73, 166-171.

Gossop, M., Stewart, D., Browne, N., \& Marsden, J. (2002). Factors associated with abstinence, lapse, or relapse to heroin use after residential treatment: Protective effect of coping responses Addiction, 97, 1259-1267.

Grella, C., Anglin, M., \& Wugalter, S. (1997). Patterns and predictors of cocaine and crack use by clients in standard and enhanced methadone maintenance treatment. American Journal of Drug \& Alcohol Abuse, 23, 15-42. 
Hubbard, R., Craddock, S., Flynn, P., Anderson, J., \& Etheridge, R. (1997). Outcomes of one year follow-up outcome in Drug Abuse Treatment Outcome Study (DATOS). Psychology of Addictive Behaviour, 11, 261-278.

Hudgins, R., McCusker, J., \& Stoddard, A. (1995). Cocaine use and risky injection and sexual behaviours. Drug \& Alcohol Dependence, 37, 7-14.

Jarvis, G., \& Parker, H. (1989). Young heroin users and crime: How do the 'new users' finance their habits? British Journal of Criminology, 29, 175-185.

Joe, G., \& Simpson, D. (1995). HIV risk, gender and cocaine use among opiate users. Drug \& Alcohol Dependence, 37, 23-28.

Keene, J. (2001). Clients with complex needs: Inter-professional practice. Oxford, UK: Blackwell Science.

Kelly, A., Carvalho, M., \& Teljeur, C. (2003). Prevalence of opiate use in Ireland 2000-2001: A 3source capture recapture study. Department of Public Health \& Primary Care, NACD. Dublin, Ireland: Stationery Office.

Kelly, F., Lynn, E., \& Long, J. (2005). Treatment demand in the Health Service Executive Eastern Region, 1998 to 2002 (Occasional Paper 15). Dublin, Ireland: Health Research Board.

Long, J., Lynn, E., \& Kelly, F. (2005). Trends in treated problem drug users in Ireland, 1998 to 2002 (Occasional Paper 17). Dublin, Ireland: Health Research Board.

Miller, N., \& Mirin, S. (1989). Multiple drug use in alcoholics: Practical and theoretical implications. Psychiatric Annals, 19, 251-255.

National Drugs Strategy. (2001). Building on experience 2001-2008. Department of Tourism, Sport and Recreation. Dublin, Ireland: Stationery Office.

Rooney, S., Kelly, G., Bamford, D., Sloan, D., \& O'Connor, J. (1999). Co-abuse of opiates and benzodiazepines. Irish Journal of Medical Science, 168, 37-41.

Stein, M. D. (1999). Medical consequences of substances abuse. Psychiatric Clinics of North America, 22, 351-370.

Teesson, M., Ross, J., Drake, S., Lynskey, M., Ali, R., Ritter, A., et al. (2006). One year outcomes for heroin dependence: Findings from the Australian Treatment Outcome Study (ATOS).Drug \& Alcohol Dependence, 83, 174-180.

UNDCP. (1997). World drug report. United Nations Drug Control Programs. Oxford, UK: Oxford University Press.

Weaver, T., Madden, P., Charles, V., Stimpson, G., \& Renton, A. (2003). Co-morbidity of substance misuse and mental illness in community mental health and substance misuse services. British Journal of Psychiatry, 183, 304-313. 